\title{
Discrete element thermomechanical modelling of rock cutting with valuation of tool wear
}

\author{
Jerzy Rojek
}

Received: 17 January 2014 / Accepted: 20 March 2014 / Published online: 15 April 2014

(C) The Author(s) 2014. This article is published with open access at Springerlink.com

\begin{abstract}
The paper presents a thermomechanical discrete element model of rock cutting process. The thermomechanical formulation of the discrete element method considers mechanical and thermal phenomena and their reciprocal influence. The thermal model developed for transient heat conduction problems takes into account conductive heat transfer at the contact between particles and convection on the free surface. The thermal and mechanical problems are coupled by consideration of: (1) heat generated due to friction which is calculated in the mechanical problem and passed to the thermal solution, (2) influence of thermal expansion on mechanical interaction between particles. Estimation of temperature dependent wear has been included into the contact model. The coupled problem is solved using the staggered scheme.The thermomechanical algorithm has been implemented in a discrete element program and applied to simulation of rock cutting with single pick of a dredge cutter head. Numerical results confirm good performance of the developed algorithm.
\end{abstract}

Keywords Discrete element method Thermomechanical . Coupling $\cdot$ Rock cutting $\cdot$ Wear

\section{Introduction}

A variety of rock-cutting technologies is used in civil as well as in mining engineering. Figure 1 shows a cutter head of a dredging machine performing rock cutting in underwater conditions. Rock cutting consists in fracturing and disinte-

J. Rojek ( $\square)$

Institute of Fundamental Technological Research, Polish Academy

of Sciences, Pawinskiego 5B, 02-106 Warsaw, Poland

e-mail: jrojek@ippt.pan.pl gration of a rock under mechanical action of a cutting tool. Rock chips are formed and separated (Fig. 2) due to combined action of shear and tensile fracture initiated in a crushing zone near the tooth tip and propagating into the intact rock.

Performance and efficiency of cutting processes are evaluated using different criteria such as cutting forces and their variation, cutting rate, specific energy and tool wear $[2,3,9,17]$. The wear leads to significant changes of the shape of rock cutting tools (Fig. 3) and it is an important factor affecting the overall efficiency of excavation works, firstly, because of its adverse effect on cutting forces, excavation rate and energy consumption, and secondly, due to the costs and delays incurred by replacements of the worn-out tools [34].

Prediction of wear is an important element in the design and optimization cutting tools. Tool wear depends on both mechanical and thermal effects in the tool-rock interaction. High temperatures, developed on the tool surface (in some cases temperature on the tool surface can reach as much as $550-800{ }^{\circ} \mathrm{C}$, cf. $\left.[20,35]\right)$ due to heat generated by friction between tool and rock, reduce the hardness of the surface and increase adhesive and abrasive wear.

Various theoretical models have been developed for rock cutting. Simple analytical models have been proposed by Evans [9] and Nishimatsu [23]. The complex stress state and crack propagation patterns involved in the process of rock cutting, however, makes it difficult for theoretical analysis. The rock failure process during cutting can be traced in more detail by appropriate numerical methods.

A number of numerical studies of rock cutting utilized the finite element method, cf. [16, 18, 19,30,39]. However, the finite element method based on the continuum mechanics theory of material modelling has serious problems in representing properly discontinuities of the mate- 


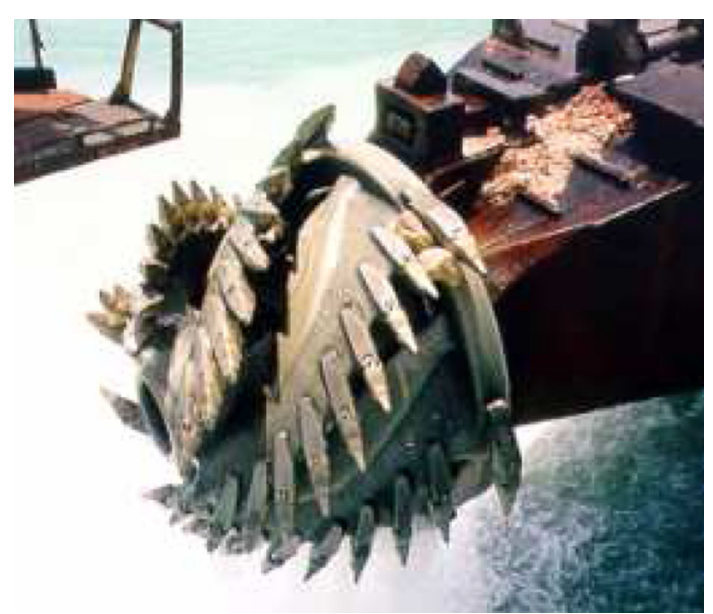

Fig. 1 Dredge cutter head

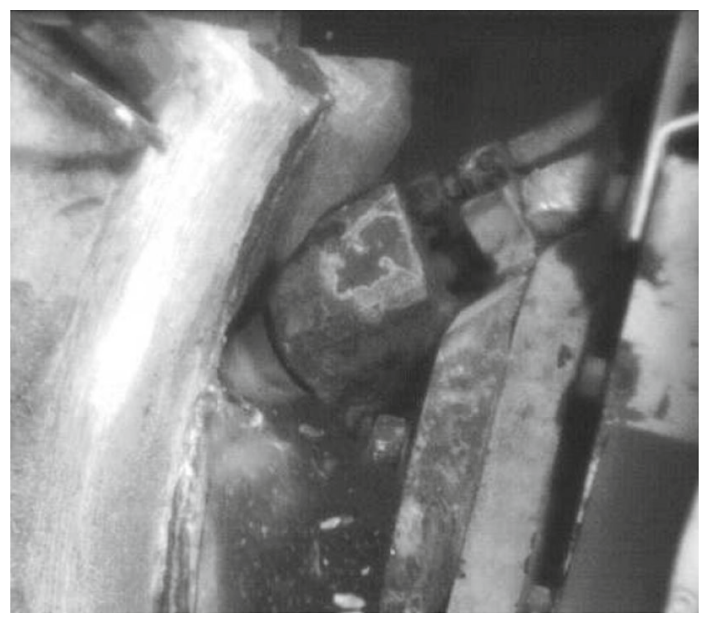

Fig. 2 Laboratory test of rock cutting (courtesy of Sandvik Mining and Construction $\mathrm{GmbH}$, Zeltweg, Austria)

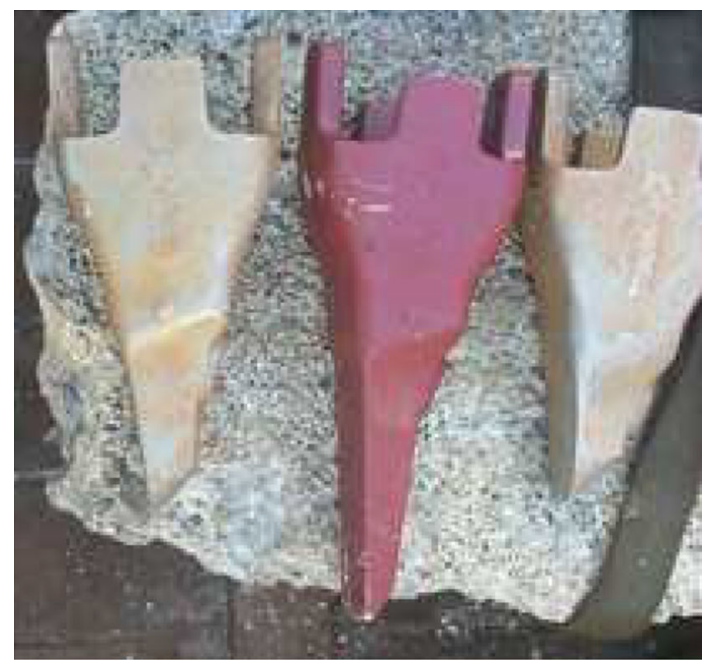

Fig. 3 Wear of rock cutting tools-new and worn dredger picks rial occurring during rock cutting [16]. Special formulations are necessary to introduce the possibility of discontinuum analysis of rock fracture [30,39]. The discrete element method can take into account most kinds of discontinuities and material failure characterized with multiple fracture, which makes it a suitable tool to study rock cutting $[14,15,26,28,31,32]$.

In order to consider the temperature dependent wear of rock cutting tools it is necessary to include thermal effects into the model. Thermal effects, including frictional heating and convective cooling of drag tools during rock cutting have been modelled numerically using 2D thermal finite difference models by Ortega and Glowka [24,25]. Temperature distribution in the tool has been obtained for assumed frictional heating and convective cooling rates. The results have been compared with experimental measurements showing quite a good performance of the simple numerical model. A two-dimensional transient heat transfer model was developed using the finite element method for the study of temperature rise during continuous drag-cutting by Loui and Karanam [20]. The effect of frictional force and cutting speed on the temperature developed at the pickrock interface was compared with the experimental data.

The heat conduction problem can also be analysed using the discrete element method. The discrete element model originally introduced to model mechanical problems [7] can be extended on thermal and thermomechanical problems. The discrete thermal element method (DTEM) proposed by Feng et al. [11] considered heat conduction within the particle using analytical integral solution for the temperature distribution over a circular domain subjected to the Neumann boundary condition. This concept introduced significant complexity into a simple formulation of the discrete element method. A simplified version of the DTEM, termed the pipe-network model, in which each particle is replaced by a simple thermal pipe-network connecting the particle centre with each contact zone associated with the particle has been developed by the same authors [12]. The lattice model of thermal pipes (contact lines) linking heat reservoirs at particle centres is commonly adopted as a thermal model in the discrete element model, cf. $[13,22,40]$. A discrete element thermal analysis can be performed independently $[12,13,40,41]$ or coupled with a mechanical problem solution $[8,22,33,36]$ as well as with other physical fields $[42,43]$.

The present work extends The discrete element model of rock cutting presented in $[26,28]$ is extended here on thermomechanical analysis. The present contains original elements in theoretical formulation, such as evaluation of temperature dependent wear, and in modelling approach to rock cutting process which has not been analysed before with the discrete element method as the coupled thermomechanical problem. 
Fig. 4 Thermo-mechanical model of rock cutting: a scheme of mechanical problem, $\mathbf{b}$ scheme of thermal problem

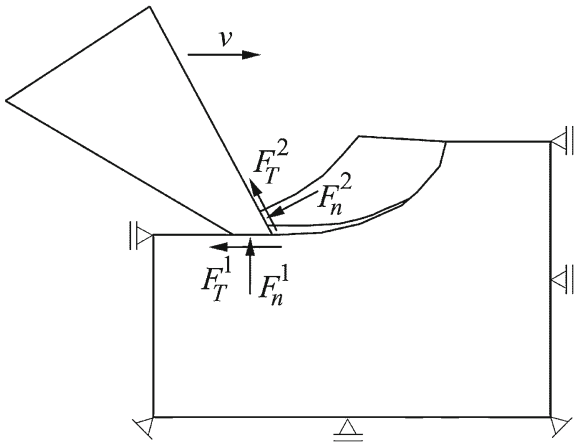

(a)

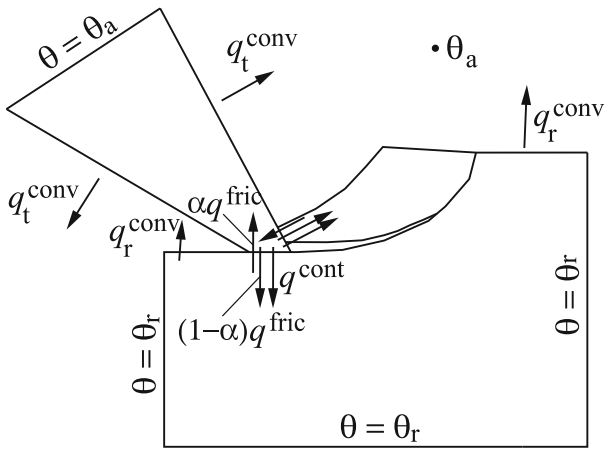

(b)

\section{Thermomechanical model of rock cutting: basic assumptions}

A rock cutting process is considered here as a coupled thermomechanical problem, in which mechanical phenomena are accompanied by correlated thermal effects. Thermomechanical model of the tool-rock system is shown schematically in Fig. 4. The main physical phenomenon analyzed in the mechanical problem is the interaction of the tool with a rock leading to a failure of the rock characterized with discontinuous material behaviour. Interaction forces between tool and rock are determined. Simultaneously heat generated by friction between the tool and rock is calculated and passed to the thermal model. The thermal model takes into account heat absorption and conduction through the tool and rock as well as convective heat transfer on the free surface of the rock and tool and heat transfer in the contact surface between the rock and tool. Changing temperature distribution is determined in the solution of the thermal problem Change of temperature cause material expansion and may produce thermal stresses. Increase of temperature influences material properties and tool wear.

In the model of rock cutting assumed in this work, the tool is considered rigid, assuming that its stiffness is sufficient to produce rock failure and its deformation is irrelevant for the purposes of modelling of rock failure. Thus no stress analysis is performed for the tool.

\section{Thermomechanical discrete element method formulation}

The numerical model of the tool-rock system allowing us to simulate a process of rock cutting as coupled thermomechanical problem has been developed within the framework of the discrete element method (DEM) employing spherical (in 3D) or cylindrical (in 2D) particles. Discrete element formulation using spherical or cylindrical particles was first proposed by Cundall and Strack [7]. The present model has been developed within the author's own implementation of DEM $[26,29]$.

\subsection{Discrete element method formulation for mechanical problem}

\section{Equations of motion}

The translational and rotational motion of rigid spherical or cylindrical elements (particles) is governed by the standard equations of rigid body dynamics. For the $i$ th element we have

$m_{i} \ddot{\mathbf{u}}_{i}=\mathbf{F}_{i}$,

$I_{i} \dot{\boldsymbol{\omega}}_{i}=\mathbf{T}_{i}$,

where $\mathbf{u}_{i}$ is the element centroid displacement in a fixed (inertial) coordinate frame $\mathbf{X}, \boldsymbol{\omega}_{i}$ - the angular velocity, $m_{i}$ - the element mass, $J_{i}$-the moment of inertia, $\mathbf{F}_{i}$-the resultant force, and $\mathbf{T}_{i}$-the resultant moment about the central axes. The form of the rotational Eq. (2) is valid for spheres and cylinders (in 2D) and is simplified with respect to a general form for an arbitrary rigid body with the rotational inertial properties represented by a second order tensor. Vectors $\mathbf{F}_{i}$ and $\mathbf{T}_{i}$ are the sums of all forces and moments applied to the $i$ th element due to external load, $\mathbf{F}_{i}^{\text {ext }}$ and $\mathbf{T}_{i}^{\text {ext }}$, respectively, the contact interactions with neighbouring spheres, $\mathbf{F}_{i j}^{\mathrm{cont}}, j=1, \ldots, n_{i}^{\mathrm{c}}$, where $n_{i}^{\mathrm{c}}$ are the number of elements being in contact with the $i$ th discrete element, and the forces and moments resulting from external damping, $\mathbf{F}_{i}^{\mathrm{damp}}$ and $\mathbf{T}_{i}^{\text {damp }}$, respectively:

$$
\begin{aligned}
& \mathbf{F}_{i}=\mathbf{F}_{i}^{\mathrm{ext}}+\sum_{j=1}^{n_{i}^{\mathrm{c}}} \mathbf{F}_{i j}^{\mathrm{cont}}+\mathbf{F}_{i}^{\mathrm{damp}}, \\
& \mathbf{T}_{\mathbf{i}}=\mathbf{T}_{\mathbf{i}}^{\mathrm{ext}}+\sum_{\mathbf{j}=\mathbf{1}}^{\mathbf{n}_{\mathbf{i}}^{\mathrm{c}}} \mathbf{s}_{\mathbf{i j}}^{\mathrm{c}} \times \mathbf{F}_{\mathbf{i j}}^{\mathrm{cont}}+\mathbf{T}_{\mathbf{i}}^{\mathrm{damp}},
\end{aligned}
$$


Fig. 5 Rheological scheme of the contact interaction: $\mathbf{a}$ bonded particle interaction model, $\mathbf{b}$ particle interaction model after debonding

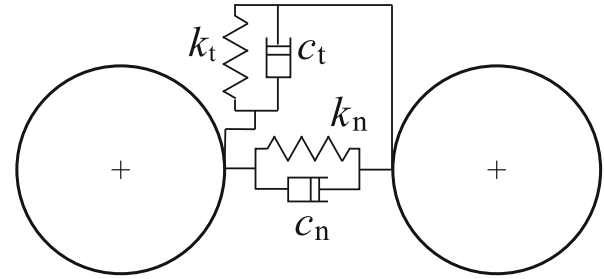

(a)

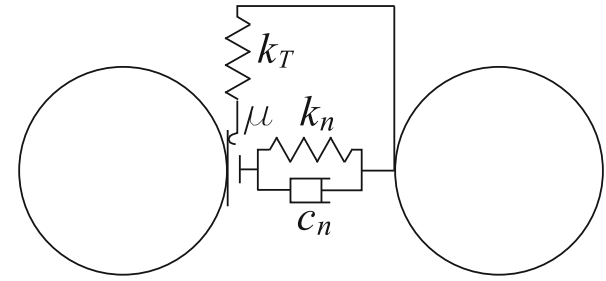

(b) where $\mathbf{s}_{\mathbf{i j}}^{\mathrm{c}}$ is the vector connecting the centre of mass of the $i$ th element with the contact point with the $j$ th element.

\section{Mechanical contact model}

The overall mechanical behaviour of the system is determined by the contact laws assumed for the particle interaction. The contact law can be seen as the material model on the microscopic level. The formulation of the contact model employs the decomposition of the contact force between two elements ${ }^{1} \mathbf{F}^{\mathrm{c}}$ into the normal and tangential components, $\mathbf{F}_{\mathrm{n}}$ and $\mathbf{F}_{\mathrm{t}}$, respectively:

$\mathbf{F}^{\mathrm{c}}=\mathbf{F}_{\mathrm{n}}+\mathbf{F}_{\mathrm{t}}=F_{\mathrm{n}} \mathbf{n}+\mathbf{F}_{\mathrm{t}}$,

where $\mathbf{n}$ is the unit normal vector at the contact point.

Modelling of rock or other cohesive materials requires contact models with cohesion allowing tensile interaction force between particle [4]. In the present formulation, rock materials are modelled using the elastic perfectly brittle model of contact interaction, in which initial bonding between neighbouring particles is assumed. The bonds are established between particles $i$ and $j$ satisfying the condition:

$g^{0}=\left\|\mathbf{x}_{j}-\mathbf{x}_{i}\right\|-r_{i}^{0}-r_{j}^{0} \leq g_{\max }^{0}$

where $r_{i}^{0}$ and $r_{j}^{0}$ are the particle radii at the initial temperature, $g^{0}$ is the overlap or gap at the contact point, and $g_{\max }^{0}$ is a length parameter, being a tolerance in contact verification. The cohesive bonds can be broken under excessive load which allows us to simulate initiation and propagation of material fracture. After decohesion, the contact is treated assuming the standard contact model with Coulomb friction. The rheological schemes of the contact interaction of bonded and unbonded particles are shown in Fig. 5.

The normal and tangential particle interaction of bonded particles (Fig. 5a) is represented by the springs connected in parallel with the dashpots providing a mechanism to dissipate contact oscillations. Thus, the normal and tangential contact forces are decomposed into the elastic, $F_{\text {ne }}$ and $\mathbf{F}_{\text {te }}$,

\footnotetext{
${ }^{1}$ In the next part of this section indices denoting the elements will be omitted.
}

and damping parts, $F_{\text {nd }}$ and $\mathbf{F}_{\mathrm{td}}$, respectively:

$$
\begin{aligned}
& F_{\mathrm{n}}=F_{\mathrm{ne}}+F_{\mathrm{nd}} \\
& \mathbf{F}_{\mathrm{t}}=\mathbf{F}_{\mathrm{te}}+\mathbf{F}_{\mathrm{td}}
\end{aligned}
$$

The elastic normal force is calculated from the linear constitutive relationship:

$F_{\text {ne }}=k_{\mathrm{n}} u_{\mathrm{n}}$

where $k_{\mathrm{n}}$ is the interface stiffness in the normal direction, and $u_{\mathrm{n}}$ is the change of the distance between the particles evaluated with respect to the distance when the cohesive bond has been established

$u_{\mathrm{n}}=\left\|\mathbf{x}_{j}-\mathbf{x}_{i}\right\|-r_{i}-r_{j}-g^{0}$

Considering the distance $g^{0}$ in the formula for $u_{\mathrm{n}}$ allows us to eliminate initial stresses in the specimen due to overlaps or gaps between bonded particles produced by a generation procedure. Thermal expansion is taken into account in calculation of the particle radii:

$r_{i}=r_{i}^{0}\left[1+\alpha_{i}\left(\theta_{i}-\theta_{i}^{0}\right)\right], \quad r_{j}=r_{j}^{0}\left[1+\alpha_{j}\left(\theta_{j}-\theta_{j}^{0}\right)\right]$

where $\alpha_{i}$ and $\alpha_{j}$ are the linear thermal expansion coefficients, and $\theta_{i}, \theta_{j}, \theta_{i}^{0}, \theta_{j}^{0}$ are the particle current and initial temperatures.

The tangential elastic force is given by the linear equation

$\mathbf{F}_{\mathrm{te}}=k_{\mathrm{t}} \mathbf{u}_{\mathrm{t}}$,

$k_{\mathrm{t}}$-interface stiffness in the tangential direction, $\mathbf{u}_{\mathrm{t}}$ relative displacement at the contact point in tangential direction. The relative tangential displacement $\mathbf{u}_{\mathrm{t}}$ is evaluated incrementally:

$\mathbf{u}_{\mathrm{t}}=\mathbf{u}_{\mathrm{t}}^{\text {old }}+\Delta \mathbf{u}_{\mathrm{t}}$

where $\mathbf{u}_{t}^{\text {old }}$ is the vector of the relative tangential displacement from the previous time step rotated to the present contact plane and $\Delta \mathbf{u}_{t}$ is the incremental relative tangential displacement

$\Delta \mathbf{u}_{t}=\mathbf{v}_{\mathrm{rt}} \Delta t$ 
with $\mathbf{v}_{t}$ being the relative tangential velocity at the contact point determined as

$\mathbf{v}_{\mathrm{rt}}=\mathbf{v}_{\mathrm{r}}^{\mathrm{c}}-v_{\mathrm{rn}} \mathbf{n}$

where $\mathbf{v}_{\mathrm{r}}^{\mathrm{c}}$ is the relative velocity at the contact point

$\mathbf{v}_{\mathrm{r}}^{\mathrm{c}}=\left(\dot{\mathbf{u}}_{j}+\omega_{j} \times \mathbf{s}_{j i}^{\mathrm{c}}\right)-\left(\dot{\mathbf{u}}_{i}+\omega_{i} \times \mathbf{s}_{i j}^{\mathrm{c}}\right)$

and $v_{\mathrm{rn}}$ is the normal relative velocity at the contact point

$v_{\mathrm{rn}}=\mathbf{v}_{\mathrm{r}}^{\mathrm{c}} \cdot \mathbf{n}$

The contact damping forces in the normal and tangential directions are given by

$$
\begin{aligned}
F_{\mathrm{nd}} & =c_{\mathrm{n}} v_{\mathrm{rn}} \\
\mathbf{F}_{\mathrm{td}} & =c_{\mathrm{t}} \mathbf{v}_{\mathrm{rt}}
\end{aligned}
$$

respectively, where $c_{\mathrm{n}}$ and $c_{\mathrm{t}}$ are the damping coefficients. The damping coefficients, $c_{\mathrm{n}}$ and $c_{\mathrm{t}}$, can be taken as appropriate fractions, $\xi_{\mathrm{n}}$ and $\xi_{\mathrm{t}}$, of the critical damping in the normal and tangential direction, $c_{\mathrm{n}}^{\mathrm{cr}}$ and $c_{\mathrm{t}}^{\mathrm{cr}}$, respectively:

$\begin{aligned} c_{\mathrm{n}} & =\xi_{\mathrm{n}} c_{\mathrm{n}}^{\mathrm{cr}} \\ c_{\mathrm{t}} & =\xi_{\mathrm{t}} c_{\mathrm{t}}^{\mathrm{cr}}\end{aligned}$

For the system of two rigid bodies with masses $m_{i}$ and $m_{j}$, connected with a spring of stiffness $k$, the critical damping $c^{\mathrm{cr}}$ is given by, cf. [4]:

$c^{\mathrm{cr}}=2 \sqrt{\frac{m_{i} m_{j} k}{m_{i}+m_{j}}}$

By taking $k=k_{\mathrm{n}}$ or $k_{\mathrm{t}}$ in Eq. (22) the critical damping $c_{\mathrm{n}}^{\mathrm{cr}}$ and $c_{\mathrm{t}}^{\mathrm{cr}}$ is obtained.

The normal tensile and tangential elastic contact forces are limited by the tensile and shear interface strengths, $R_{n}$ and $R_{t}$, respectively:

$F_{\text {ne }} \leq R_{\mathrm{n}}, \quad\left\|\mathbf{F}_{\text {te }}\right\| \leq R_{\mathrm{t}}$

Cohesive bonds are broken instantaneously when the interface strength is exceeded either by the tangential contact force or by the tensile contact force.

In the absence of cohesion the normal contact force can be compressive only $\left(F_{n} \leq 0\right)$ and tangential contact force can be nonzero due to friction. The frictional contact can be treated as a problem analogous to that of elastoplasticity. This analogy allows us to calculate the friction force employing the standard radial return algorithm. First a trial state is calculated

$\mathbf{F}_{\mathrm{t}}^{\mathrm{trial}}=\mathbf{F}_{\mathrm{t}}^{\mathrm{old}}+k_{\mathrm{t}} \mathbf{v}_{\mathrm{rt}} \Delta t$ and then the slip condition is checked

$\phi^{\text {trial }}=\left\|\mathbf{F}_{\mathrm{t}}^{\text {trial }}\right\|-\mu\left|F_{\text {ne }}\right|$

If $\phi^{\text {trial }} \leq 0$, we have stick contact and the friction force is assigned the trial value

$\mathbf{F}_{\mathrm{t}}^{\text {new }}=\mathbf{F}_{\mathrm{t}}^{\mathrm{trial}}$

otherwise (slip contact) a return mapping is performed giving

$\mathbf{F}_{\mathrm{t}}^{\text {new }}=\mu\left|F_{\text {ne }}\right| \frac{\mathbf{F}_{\mathrm{t}}^{\text {trial }}}{\left\|\mathbf{F}_{\mathrm{t}}^{\mathrm{trial}}\right\|}$

\section{Background damping}

The contact damping previously described is a function of the relative velocity of the contacting bodies. It is sometimes necessary to apply damping, referred here as background damping, for non-contacting particles to dissipate their energy. The background damping is represented by the terms $\mathbf{F}_{i}^{\text {damp }}$ and $\mathbf{T}_{i}^{\text {damp }}$ in equations of motion (1) and (2). Two types of the background damping have been implemented:

- viscous damping

$\mathbf{F}_{i}^{\text {damp }}=-\varepsilon^{\mathrm{vt}} m_{i} \dot{\mathbf{u}}_{i}$,

$\mathbf{T}_{i}^{\text {damp }}=-\varepsilon^{\mathrm{vr}} I_{i} \boldsymbol{\omega}_{i}$,

- non-viscous damping

$\mathbf{F}_{i}^{\text {damp }}=-\varepsilon^{\mathrm{nvt}}\left\|\mathbf{F}_{i}\right\| \frac{\dot{\mathbf{u}}_{i}}{\left\|\dot{\mathbf{u}}_{i}\right\|}$,
$\mathbf{T}_{i}^{\text {damp }}=-\varepsilon^{\mathrm{nvr}}\|\mathbf{T}\| \frac{\boldsymbol{\omega}_{i}}{\left\|\boldsymbol{\omega}_{i}\right\|}$.

where $\varepsilon^{\mathrm{vt}}, \varepsilon^{\mathrm{vr}}, \varepsilon^{\mathrm{nvt}}$ and $\varepsilon^{\mathrm{nvr}}$ are damping constants. The viscous damping is proportional to the magnitude of the velocity, while the non-viscous damping is proportional to the magnitude of the resultant force and resultant moment (Fig. 6).

\subsection{Thermal formulation of the discrete element method}

Thermal formulation of the discrete element method introduced in this work is based on the assumption that the temperature difference inside particles is negligible and the temperature can be considered uniform within particles. Following this assumption heat conduction inside particles is neglected whereas heat transfer to and from particles through their boundary is considered. Such a simplification of the heat conduction problem is typical for the lumped capacitance model, also called the lumped system analysis [4]. This assumption 


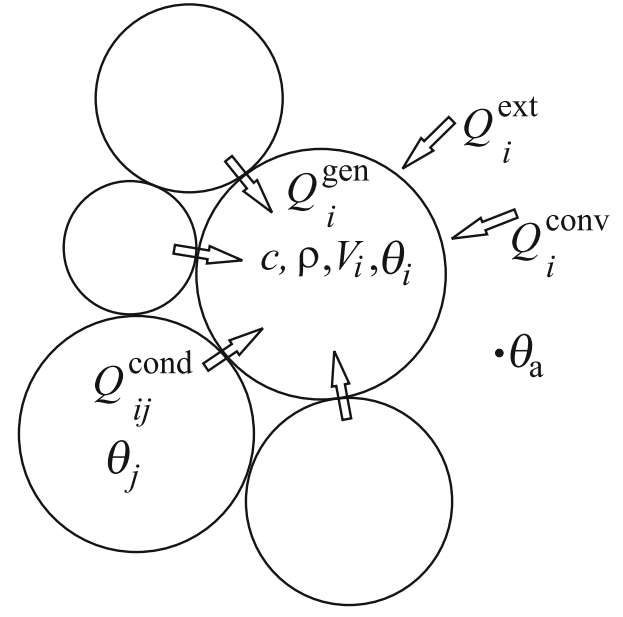

Fig. 6 Scheme of the heat conduction problem for a discrete element

is justified for the discrete element model employing relatively small particles and it is consistent with the formulation of the mechanical problem. Similarly as the mechanical problem is governed by the contact interaction, the heat conduction problem is governed by the conductive heat transfer at the particle contacts.

The scheme of the heat transfer for a single particle is shown in Fig. 6. The thermal model is expressed mathematically by the heat balance equation, which can be written for a single particle in the following form:

$m_{i} c \dot{\theta}_{i}=Q_{i}$,

where: $m_{i}$-particle mass, $c$-specific heat, $\theta_{i}$-particle temperature, $Q_{i}$ - heat sources or heat fluxes per single particle. $Q_{i}$ includes externally supplied heat source $Q_{i}^{\text {ext }}$, heat generated through friction dissipation and absorbed by the particle $Q_{i j}^{\text {gen }}$, heat conducted through the contact interface $Q_{i j}^{\text {cont }}$, and convective and radiative heat transfer between particles and environment on the free surface, $Q_{i}^{\text {conv }}$ and $Q_{i}^{\text {rad }}$

$Q_{i}=Q_{i}^{\mathrm{ext}}+\sum_{j=1}^{n_{c}} Q_{i j}^{\mathrm{gen}}+\sum_{j=1}^{n_{c}} Q_{i j}^{\mathrm{cont}}+Q_{i}^{\mathrm{conv}}+Q_{i}^{\mathrm{rad}}$

where $n_{c}$ is the number of particles being in contact with the $i$ th particle.

\subsection{Thermomechanical contact}

Except for mechanical effects thermal phenomena, heat transfer and frictional heat generation, are included in the interaction model of contacting particles (Fig. 7). Particleto-particle conductive heat transfer rate $Q_{i j}^{\text {cont }}$ is given as follows:

$Q_{i j}^{\text {cont }}=-h^{\text {cont }} A^{\text {cont }}\left(\theta_{i}-\theta_{j}\right)$

where $\theta_{i}$ and $\theta_{j}$ are the contacting particle temperatures, $A^{\text {cont }}$ is the contact area, and $h^{\text {cont }}$ is the thermal contact conductance coefficient defining the conductivity through the contact interface between two contacting surfaces. In general case of a contact of different bodies or particles, the thermal contact conductance, is dependent on the surface roughness, material properties, interface temperature and interface pressure [5,21]. It is sometimes convenient to express heat transfer at the contact in terms of one parameter $H^{\text {cont }}=h^{\text {cont }} A^{\text {cont }}$, then Eq. (34) can be rewritten as [40]:

$Q_{i j}^{\text {cont }}=-H^{\text {cont }}\left(\theta_{i}-\theta_{j}\right)$

Heat generation through frictional dissipation is calculated using the following formula

$Q^{\text {gen }}=\chi\left|F_{\mathrm{t}} v_{\mathrm{rt}}^{\mathrm{ir}}\right|$,

where $F_{\mathrm{t}}$ is the friction force, $v_{\mathrm{rt}}^{\mathrm{ir}}$ is the irreversible part of the relative tangential velocity, and $0 \leq \chi \leq 1$ is the part of the friction work converted to heat. Heat generated at the contact point is absorbed by the contacting particles

$Q^{\mathrm{gen}}=Q_{i j}^{\mathrm{gen}}+Q_{j i}^{\mathrm{gen}}$

If the particles are of the same materials, it is assumed that the heat is absorbed equally by the particles:

$Q_{i j}^{\mathrm{gen}}=Q_{j i}^{\mathrm{gen}}=0.5 Q^{\mathrm{gen}}$

In a general case, when the particle thermal properties can be different, heat absorbed by each of the contacting particle is assumed to be proportional to the thermal effusivity of the particle materials
Fig. 7 Thermomechanical contact scheme for a pair of particles: a mechanical contact interaction, $\mathbf{b}$ thermal contact effects

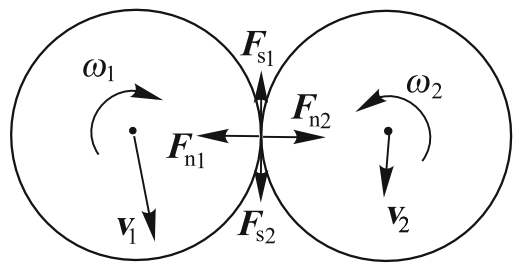

(a)

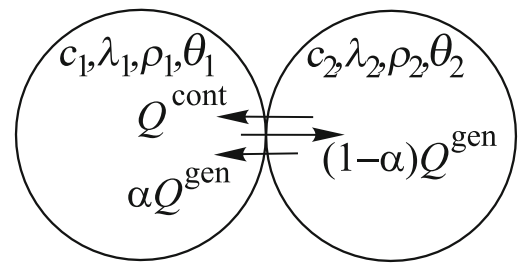

(b) 
with the effusivity $e$ being defined as

$e=\sqrt{\lambda \rho c}$

where $\lambda$ is the thermal conductivity, $c$ is the specific heat capacity, and $\rho$ is the density. The heat partition coefficient $\alpha$ is given by the following equation

$\alpha=\frac{e_{i}}{e_{i}+e_{j}}$

\subsection{Convective heat transfer}

Convective heat transfer between particles and the environment can be determined from Newton's law of cooling as [4]:

$Q_{i}^{\text {conv }}=-h^{\text {conv }} \bar{A}_{i}\left(\theta_{i}-\theta_{\mathrm{a}}\right)$

where $\theta_{\mathrm{a}}$ is the ambient temperature, $h^{\text {conv }}$ is the convective heat transfer coefficient, and $\bar{A}_{i}$ is the surface area assigned to the boundary particle as

$\bar{A}_{i}=\xi r_{i}$

with $\xi$ being the coefficient given by

$\xi=\frac{L_{\text {bound }}}{\sum_{i} r_{i}}$

where summation is performed over all the particles on the convective boundary, and $L_{\text {bound }}$ is the length of the boundary with the convection condition.

3.5 Thermomechanical coupling in the discrete element method

Thermo-mechanical problem defined by the system of coupled equations formed by the equations of motion (1) and (2) and the heat balance Eq. (32)

$m_{i} \ddot{\mathbf{u}}_{i}=\mathbf{F}_{i}$,

$I_{i} \dot{\boldsymbol{\omega}}_{i}=\mathbf{T}_{i}$,

$m_{i} c \dot{\theta}_{i}=Q_{i}$

with appropriate initial conditions. Equations (45) and (46) are coupled with Eq. (47) by consideration of the following effects:

- frictional heat generation,

- thermal expansion of the particles and its effect on particle interaction.

The system of coupled equations is solved using the staggered solution scheme, in which the mechanical and thermal problems are analysed separately.

1. Solution of the mechanical problem.
Equations (45) and (46) are integrated in time using the explicit central difference scheme. Employing the equations for the known configuration at the time $t_{n}$ the solution for the time $t_{n+1}$ is obtained in the following way:

$\ddot{\mathbf{u}}_{i}^{n}=\frac{\mathbf{F}_{i}^{n}}{m_{i}}$,

$\dot{\mathbf{u}}_{i}^{n+1 / 2}=\dot{\mathbf{u}}_{i}^{n-1 / 2}+\ddot{\mathbf{u}}_{i}^{n} \Delta t$,

$\mathbf{u}_{i}^{n+1}=\mathbf{u}_{i}^{n}+\dot{\mathbf{u}}_{i}^{n+1 / 2} \Delta t$,

$\dot{\omega}_{i}^{n}=\frac{\mathbf{T}_{i}^{n}}{I_{i}}$,

$\omega_{i}^{n+1 / 2}=\omega_{i}^{n-1 / 2}+\dot{\omega}_{i}^{n} \Delta t$,

$\Delta \psi_{i}=\omega_{i}^{n+1 / 2} \Delta t$.

Thermal expansion of the particles and resulting thermal components of the interaction forces are considered in the solution of the mechanical problem. In the considered problem, thermally induced stresses in rock are of minor importance, but in other problems they may be the main factor leading to rock damage [36]. Heat generated by friction is evaluated in Eqs. (45) and (46) and passed to Eq. (47).

2. Solution of the thermal problem

Heat conduction Eq. (47) is integrated in time using the explicit forward Euler scheme

$\theta_{i}^{n+1}=\theta_{i}^{n}+\frac{Q_{i}^{n} \Delta t}{m_{i} c}$.

The thermal problem is solved on the modified particle configuration determined in the solution of the mechanical problem. Particle temperatures evaluated in the solution of the thermal problem are passed to the solution of the mechanical problem.

The explicit time integration scheme of the coupled thermomechanical problem is conditionally stable. The time integration step is limited by the critical step $\Delta t_{\mathrm{cr}}$ :

$\Delta t_{\mathrm{cr}}=\min \left(\Delta t_{\mathrm{cr}}^{\mathrm{mech}}, \Delta t_{\mathrm{cr}}^{\mathrm{term}}\right)$,

where $\Delta t_{\mathrm{cr}}^{\text {mech }}$ is the critical time step for the solution of the mechanical problem depending on the highest eigenfrequency of the discrete system $\Omega_{\max }$

$\Delta t_{\mathrm{cr}}^{\text {mech }}=\frac{2}{\Omega_{\max }}$,

and $\Delta t_{\mathrm{cr}}^{\mathrm{term}}$ is the critical time step for the solution of the thermal problem. The critical time step for the solution of the thermal problem can be estimated by the critical value for the one-dimensional heat conduction problem [4]. 
$\Delta t_{\mathrm{cr}}^{\mathrm{term}} \approx \frac{l_{\min }}{2 a}$,

where $l_{\min }$ is the minimum particle centre distance and $a$ is the thermal diffusivity

$a=\frac{\lambda}{\rho c}$.

\section{Wear model}

Wear of rock cutting tools is dominated by abrasive and adhesive mechanisms [35]. Abrasive wear is one of the most important mechanisms in cutting of hard rocks especially in the presence of quartzite. Scraping of the rock surface leads to high temperatures, which softens the steel body and hardmetal tip, resulting in increasing wear of adhesive character. Adhesive wear is typical for heat generating rock of low abrasivity. Different mechanisms often act in parallel.

Wear of rock cutting tools depends on many factors, including rock/soil properties, tool characteristics and cutting process parameters [35]. Based on the experimental data different empirical wear prediction methods for rock cutting tools have been developed, cf. [6,34]. In the approach adopted in this paper, the wear evaluation is included in the simulation of rock cutting process. The main motivation has been to increase possibilities to predict wear of rock cutting tools under different process conditions taking into account both mechanical and thermal effects.

\subsection{Archard model of wear}

Among the quantitative models of wear the classical formula of Archard [1] is still widely used. Its validity for rock cutting has been confirmed recently by experimental studies [37]. The Archard model assumes that the wear rate $\dot{w}$ is proportional to the contact pressure $p_{n}$ and to the slip velocity $v_{T}$

$\dot{w}=k \frac{p_{n} v_{T}}{H}$,

where $H$ denotes the hardness of worn surface and $k$ is a dimensionless wear parameter. The Archard model was derived originally for adhesive wear, the same form of equation, however, can be obtained for abrasive wear, cf. [27]. Values of adhesive and abrasive wear constants $k$ for different combinations of materials can be determined in laboratory tests.

\subsection{Wear model accounting for thermal effects}

Influence of temperature on wear can be taken into account by adaptation of the law of Archard [1] given by Eq. (59). Thermal effects can be captured approximately by taking hardness $H$ changing with temperature $\theta$
$H=H(\theta)$.

Taking this into account in Eq. (59) we have

$\dot{w}=k \frac{p_{n} v_{T}}{H(\theta)}$.

\subsection{Numerical implementation of wear evaluation algorithm}

The tool wear $w$, i.e. the amount (depth) of removed material is obtained by integrating the wear rate $\dot{w}$ in time

$w=\int \dot{w} \mathrm{~d} t$

The Archard law given by Eq. (61) has been implemented in the thermomechanical discrete element model presented earlier. Distribution of wear on the tool surface is estimated and the tool shape is modified according to the calculated wear. Wear is a relatively slow process. In the numerical algorithm developed wear is accelerated using scaled wear constants.

The developed numerical algorithm of wear evaluation takes advantage of the tool discretization with discrete elements. This will allow us to easily modify the shape of the tool. The tool shape is changed eliminating particles if the accumulated wear exceeds the particle diameter. The tool shape is modified continuously during the analysis.

\section{Numerical example}

\subsection{Problem definition}

2D simulation of rock cutting with one pick of a dredge cutterhead has been performed in order to verify performance of the discrete element model developed. Cuttersuction dredgers are equipped with cutter head (Fig. 1), which can be used for disintegration of hard rocks. Rock cutting during dredging is performed under water and accurate modelling of rock cutting should take into account influence of the hydrostatic and pore water pressures [35]. Here, these effects will be neglected assuming working conditions for relatively shallow water. Another effect, water cooling of cutting tools, has been considered in the solution of the thermal problem.

Figure 8 shows a work scheme of a dredge cutter head. The picks follow cycloidal trajectories resulting from the swing motion and rotation of the cutter head. The teeth cut in a rock during a part of the revolution and cool off in water the rest of the revolution when the teeth rotate in water.

Simulation of a complete cutter head would require excessively large computational cost. Numerical analysis has been performed for one pick in an undercutting operation using 


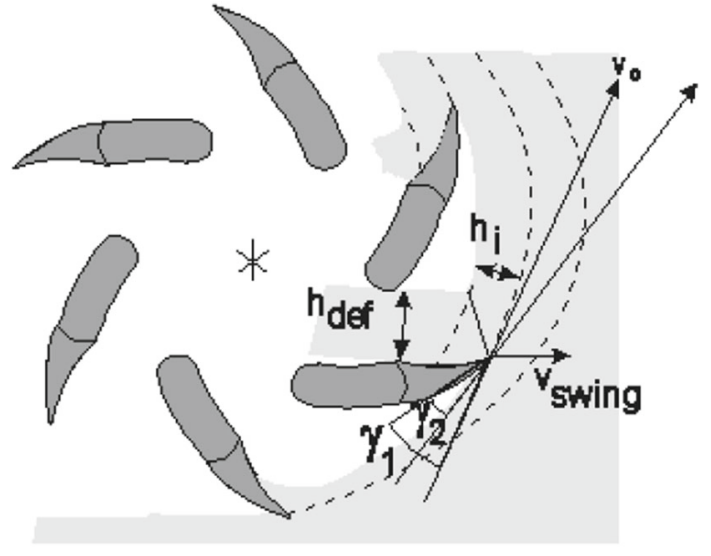

Fig. 8 Scheme of work of a dredge cutter head

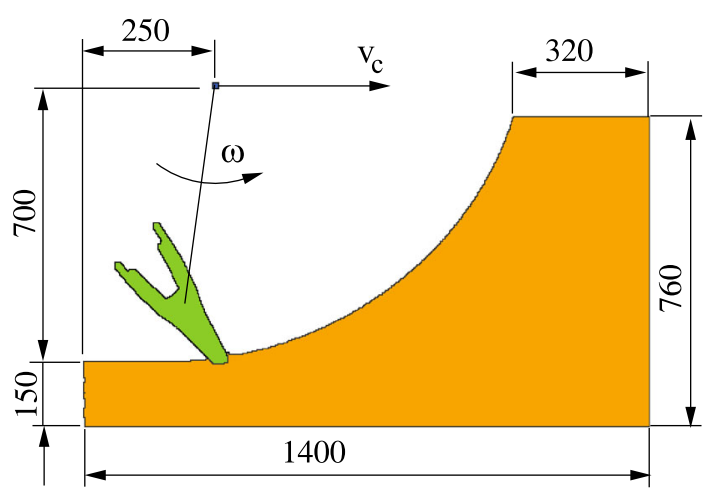

Fig. 9 Model geometry for simulation of rock cutting with one pick of a dredge cutter head

a model shown in Fig. 9. Three cycles consisting of rock cutting with tool heating and subsequent non-cutting rotation with tool cooling have been analysed. The swing velocity of the cutter head was assumed $0.2 \mathrm{~m} \mathrm{~s}^{-1}$, and angular velocity $1.6204 \mathrm{~s}^{-1}$, which with the distance of the tooth from the axis of rotation $0.7 \mathrm{~m}$ gives circumferential velocity $1.134 \mathrm{~m} \mathrm{~s}^{-1}$.

Mechanical properties of the rock are assumed the following: Young modulus $E=18 \mathrm{GPa}$, Poisson ratio $v=$ 0.18 , unconfined compression strength $\sigma_{c}=60 \mathrm{MPa}$, and tensile strength $\sigma_{t}=7 \mathrm{MPa}$. Thermal properties have been taken as follows: for the rock heat capacity $c=$ $1,970 \mathrm{~J} /(\mathrm{kg} \mathrm{K})$, heat conductivity $\lambda=5 \mathrm{~W} /(\mathrm{m} \mathrm{K})$, and linear thermal expansion $\alpha=10 \times 10^{-6} \mathrm{~K}^{-1}$, and for the steel heat capacity $\mathrm{c}=450 \mathrm{~J} /(\mathrm{kg} \mathrm{K})$, and heat conductivity $\lambda=60 \mathrm{~W} /(\mathrm{mK})$. The densities of the rock and steel have been taken, $\bar{\rho}=7,830 \mathrm{~kg} \mathrm{~m}^{-3}$ and $\bar{\rho}=2,500 \mathrm{~kg} \mathrm{~m}^{-3}$, respectively. Normal values of the heat transfer coefficient for water cooling are between 5,000 and $25,000 \mathrm{~W} /\left(\mathrm{m}^{2} \mathrm{~K}\right)$ $[24,35]$, here a low value of $5,000 \mathrm{~W} /\left(\mathrm{m}^{2} \mathrm{~K}\right)$ has been assumed.

\subsection{Discrete element model}

The rock sample of the shape shown in Fig. 9 is represented by an assembly of randomly distributed 92,000 discs of radii $1-1.5 \mathrm{~mm}$. The compaction of the assembly is characterized by the average porosity $n=0.12$. The rigid tool is modelled with 5,400 discs of equal radius of $1 \mathrm{~mm}$. The porosity of the particle discretization amounts to 0.13 .

The key issue in the discrete element method simulation is determination of micromechanical parameters yielding required macroscopic properties. There are different theoretical and numerical methods to find micro-macro relationships. A convenient method based on dimensional analysis have been proposed in [14] and successfully employed in $[10,28,38]$. Using the dimensionless micro-macro relationships given in [28] the following discrete element parameters have been evaluated: $k_{\mathrm{n}}=20 \mathrm{GPa}, k_{\mathrm{t}}=4 \mathrm{GPa}$, $R_{\mathrm{n}}=R_{\mathrm{t}}=0.1 \mathrm{MN} \mathrm{m}^{-1}$. The Coulomb friction coefficient characterizing the frictional particle interaction after debonding has been assumed $\mu=0.8$.

The densities $\bar{\rho}$ given above for the rock and steel are bulk densities. The particle material $\rho$ density should be evaluated taking into account the porosity:

$\rho=\frac{\bar{\rho}}{1-n}$.

The main micromechanical parameter employed in the thermal formulation is the thermal contact conductance $H^{\text {cont }}$. In case of rock modelling, the discrete element method is used as a discretization method-discrete elements do not represent separate particles which come into contact. The thermal contact conductance for the rock model can be estimated assuming that the heat flux transferred in the contact is equivalent to the heat flux in a bar connecting the particle centres shown in Fig. 10:

$-H^{\mathrm{cont}}\left(\theta_{i}-\theta_{j}\right)=-\lambda \frac{A^{\mathrm{bar}}}{l}\left(\theta_{i}-\theta_{j}\right)$

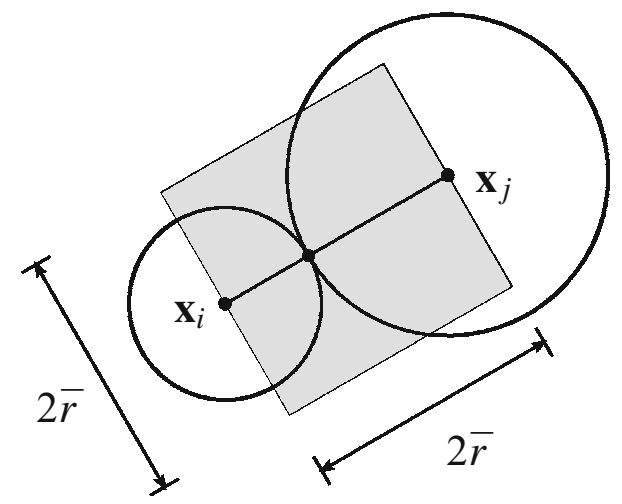

Fig. 10 Equivalence of two particles to a bar in a heat conduction problem 
where $A^{\text {bar }}$ is the bar cross-section area and $l$ its length. Taking $A=2 \bar{r} b$ and $l=2 \bar{r}$ ( $\bar{r}$ being the arithmetic mean of the contacting particle radii and $b$ - the thickness) we have the thermal contact conductance given by

$H^{\text {cont }}=\lambda b$.

In our case, the thickness $b$ for the 2D model is assumed $1 \mathrm{~m}$. It must be remarked that the micro-macro relationship (65) is approximate only and it does not take into account characteristics of the particle assembly (density of connections or coordination number). Similarly to the analysis performed in [28] for mechanical parameters it would be possible to investigate the dimensionless parameter $H^{\text {cont }} /(\lambda d)$ with $d$ being a length parameter $(d=b$ for $2 \mathrm{D}, d=\bar{r}$ for 3D).

Convective heat transfer between the tool and water is evaluated using Eq. (42) assuming the water temperature $\theta_{w}=283 \mathrm{~K}$. For the rock-tool mechanical interaction the following set of parameters has been assumed: $k_{\mathrm{n}}=k_{\mathrm{t}}=$ $50 \mathrm{GPa}, \mu=0.4$. The coefficient $\chi$ which determines the part of the friction work converted to heat in Eq. (36) is assumed 0.85 . The conductive heat transfer at the contact between the tool and rock is defined analogously to Eq. (42) as:

$Q_{i}^{\text {cont }}=-h^{\mathrm{t}-\mathrm{r}} \bar{A}_{i}\left(\theta_{\text {tool }}-\theta_{\text {rock }}\right)$

where $\theta_{\text {tool }}$ and $\theta_{\text {rock }}$ are the tool and rock surface temperatures and the area $\bar{A}_{i}$ is defined similarly as in Eq. (42). A constant value of the thermal contact conductance $h^{\mathrm{t}-\mathrm{r}}=$ $1,500 \mathrm{~W} /\left(\mathrm{m}^{2} \mathrm{~K}\right)$ has been assumed.

The set of the data is completed with the parameters of the wear model, the temperature dependent hardness $H$ and dimensionless Archard coefficient $k$. The rock cutting tool is made of steel whose hardness measured in pressure units (Brinell hardness) as a function of temperature is given in Table 1. The dimensionless Archard coefficient $k$ has been estimated in laboratory tests (Fig. 11) in the range 0.0020.003 . The average value $k=0.0025$ has been scale 10,000 times in order to obtain significant shape changes in short time.

\subsection{Numerical results}

Results of the analysis are shown in Figs. 12, 13, 14, 15, 16, 17 and 18. Failure of rock during cutting is shown in Fig. 12. Failure typical for brittle rock can be observed. Temperature

Table 1 Tool hardness as a function of temperature

\begin{tabular}{lcccccc}
\hline Temperature & $0{ }^{\circ} \mathrm{C}$ & $200{ }^{\circ} \mathrm{C}$ & $300{ }^{\circ} \mathrm{C}$ & $400{ }^{\circ} \mathrm{C}$ & $500^{\circ} \mathrm{C}$ & $600{ }^{\circ} \mathrm{C}$ \\
\hline Brinell hardness & 500 & 491 & 480 & 439 & 362 & 241 \\
\hline
\end{tabular}

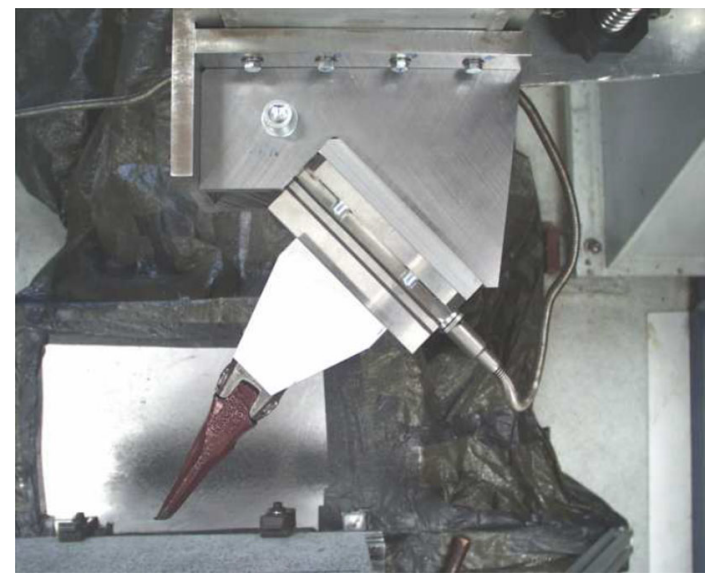

Fig. 11 Setup of a laboratory wear test

distribution at different instants of the first cut is shown in Fig. 13. An increase of tool temperature due to heat generated by friction in the contact between the rock and tool can be observed. We can see high temperature at the tool surface in the contact area and a fast drop of temperature with the distance from the surface. Steep thermal gradients are also predicted by other theoretical and numerical studies $[20,24,35]$. As expected, during the cooling phase the maximum temperature and temperature gradients decrease due to convective heat transfer at the tool surface and heat conduction through the tool body, which can be seen in Fig. 14. Variation of the maximum tool temperature during repeated heating and cooling in water is shown in Fig. 15. The temperature rises during cutting and drops during cooling in water in each cycle, the temperature peaks at the end of subsequent cycles are higher and mean temperature increases. If we continued our analysis, after certain number of cycles, a stationary state in which mean temperature and temperature peaks would stabilize. In this state the amount of energy absorbed by the tool during heating would be equal to that released to the cooling water. Figure 16 shows accumulated wear on the tooth surface at different instants of the first tooth pass of cutting. Maximum wear amounts are localized in the areas with the most intensive friction and heating. Since the wear coefficients have been upscaled the change of the tool shape due to wear is visible even after the first cut (Fig. 17). The tool wear is quantified by the curve showing the tooth mass loss in Fig. 18.

\section{Conclusions}

Extension of the discrete element formulation on thermal and thermomechanical problems has allowed us to analyse a complex practical problem of rock cutting taking into account both mechanical and thermal effects and their reciprocal 
Fig. 12 Thermomechanical simulation of rock cutting with a pick of a dredge cutter head-failure mode. a $\mathrm{t}=0.01 \mathrm{~s}, \mathbf{b} \mathrm{t}=0.2 \mathrm{~s}, \mathbf{c}$ $\mathrm{t}=0.4 \mathrm{~s}, \mathbf{d ~ t}=0.65 \mathrm{~s}$

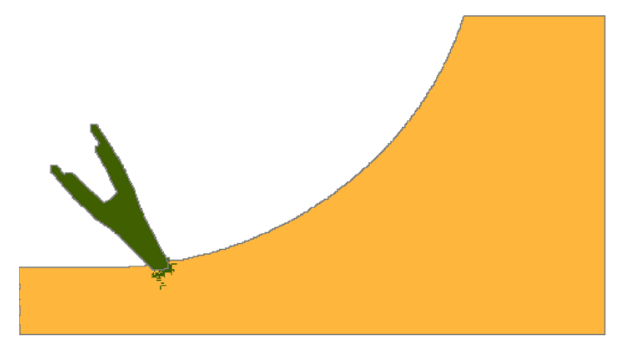

(a)

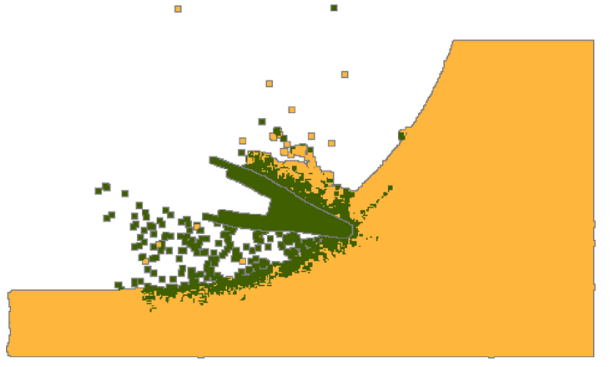

(c)

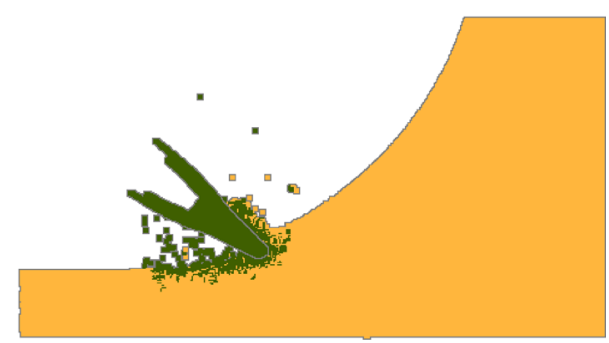

(b)

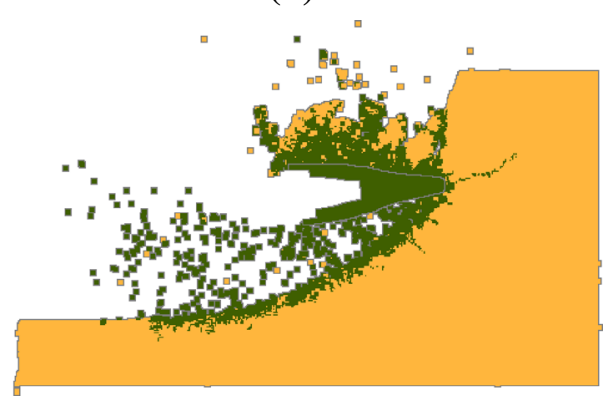

(d)

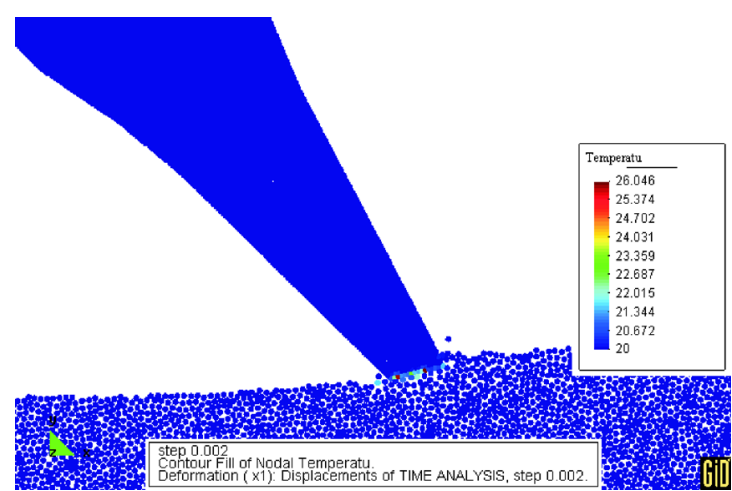

(a)

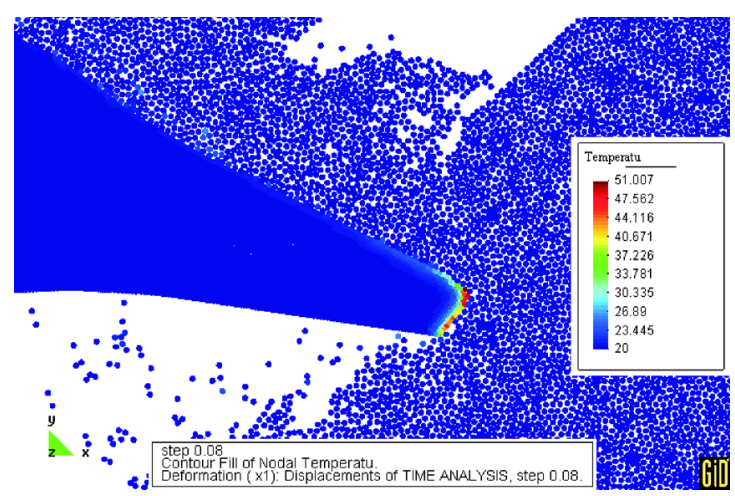

(c)

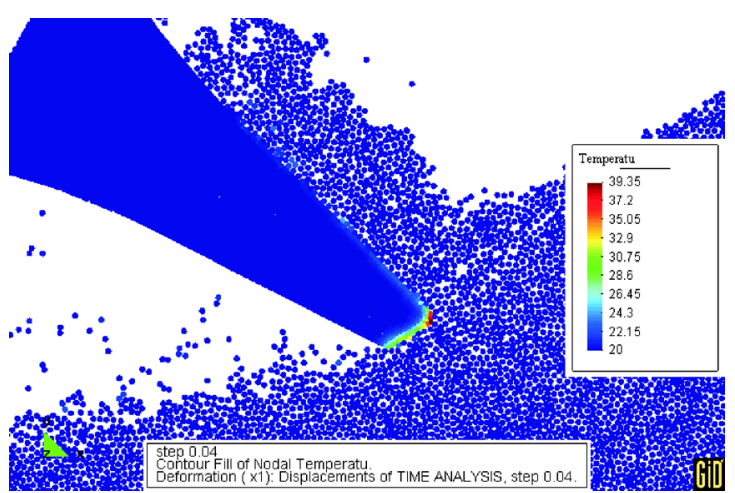

(b)

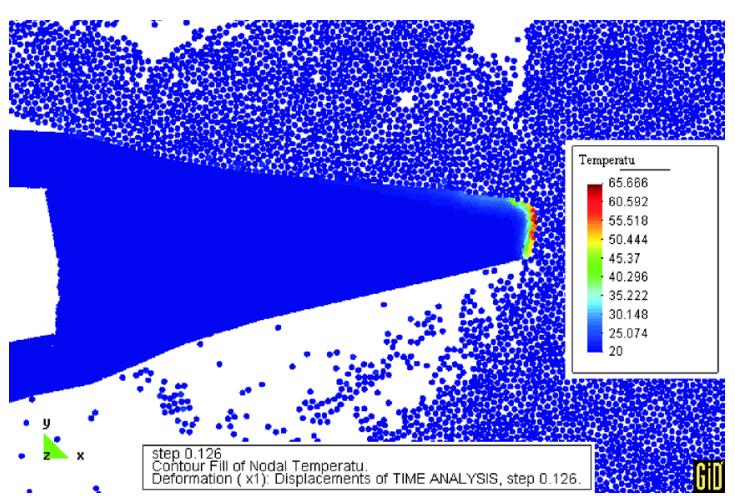

(d)

Fig. 13 Thermomechanical simulation of rock cutting with a pick of a dredge cutter head-temperature evolution during the first cut. a $\mathrm{t}=0.01 \mathrm{~s}$, b t $=0.2 \mathrm{~s}, \mathbf{c t}=0.4 \mathrm{~s}, \mathbf{d ~ t}=0.65 \mathrm{~s}$ 
Fig. 14 Thermomechanical simulation of rock cutting with a pick of a dredge cutter head-temperature evolution during cooling after the first cut. $\mathbf{a t}=0.68 \mathrm{~s}, \mathbf{b} \mathrm{t}=0.78 \mathrm{~s}, \mathbf{c}$ $\mathrm{t}=1.48 \mathrm{~s}, \mathbf{d ~ t}=2.00 \mathrm{~s}$

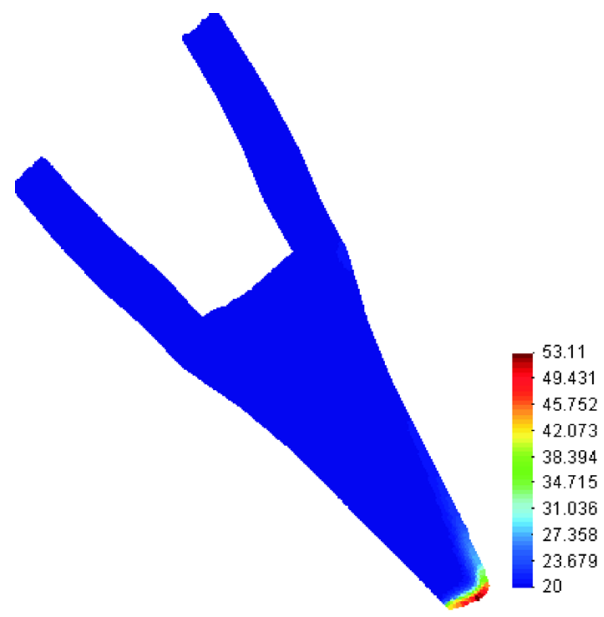

(a)

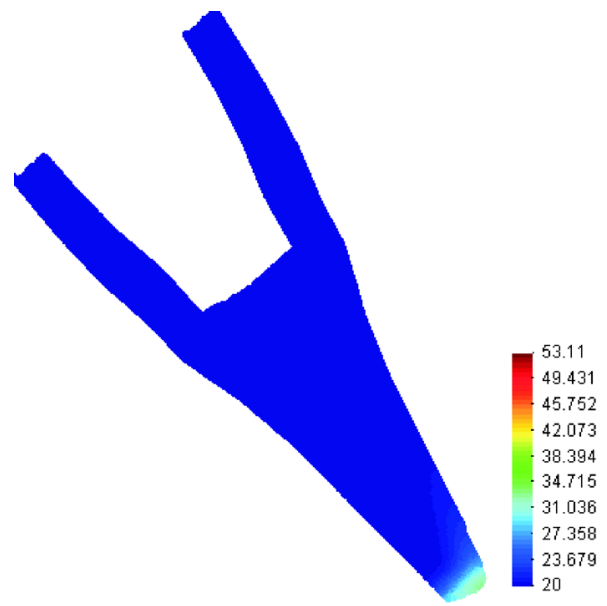

(c)

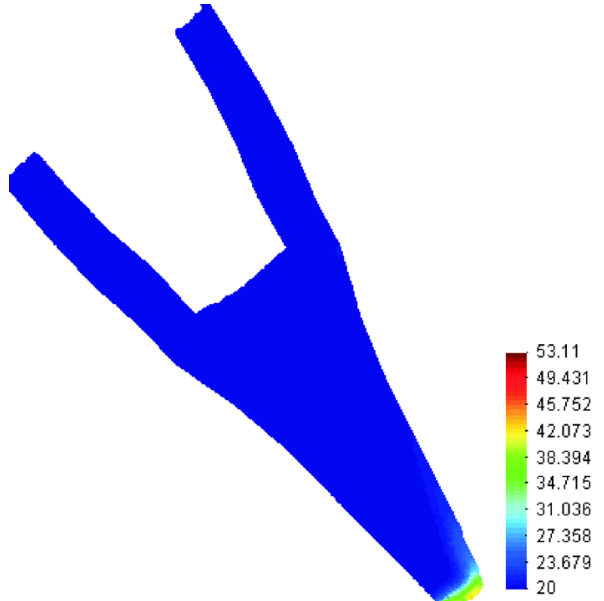

(b)

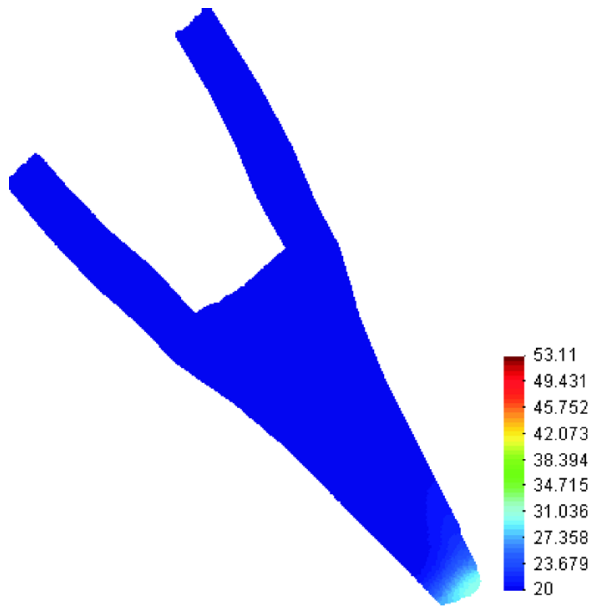

(d)

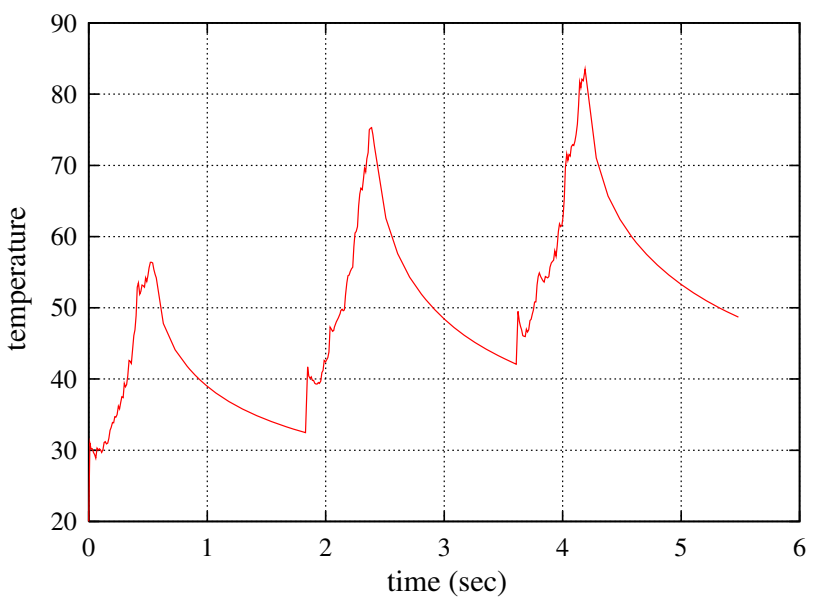

Fig. 15 Thermomechanical simulation of rock cutting with a pick of a dredge cutter head — variation of maximum tooth temperature during three cycles of cutting and subsequent cooling influence. Thermomechanical model of rock cutting enables more realistic treatment of tool wear which depends both on mechanical as well as thermal effects.

The thermal and thermomechanical discrete element method formulation contains original elements. The thermal formulation is based on the assumption of the uniform temperature in the discrete element. Heat conduction is modelled by the heat transfer at the contact between particles, which is consistent with the formulation of the mechanical problem in the discrete element method in which macroscopic material behaviour is governed by the contact interaction.

Numerical results confirm a correct performance of the developed thermomechanical formulation of the discrete element method. The results of rock cutting simulation show qualitative agreement with theoretical expectations and practical observations. 


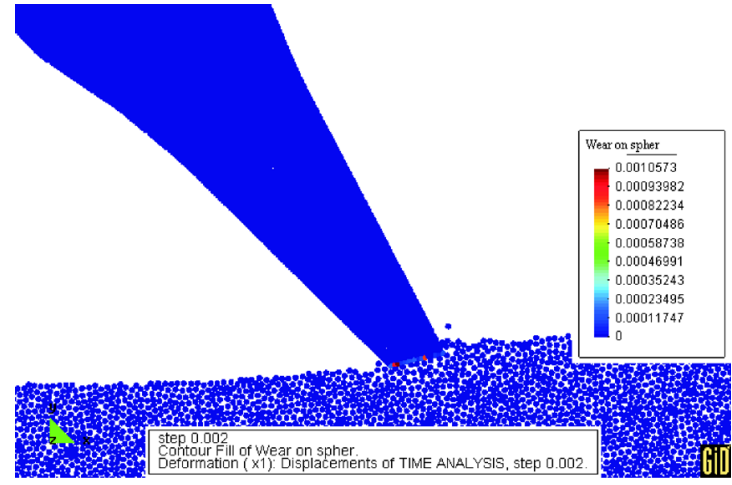

(a)

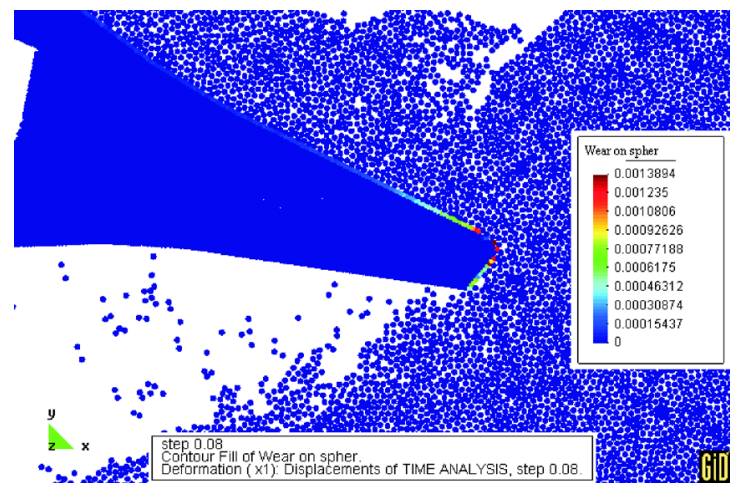

(c)

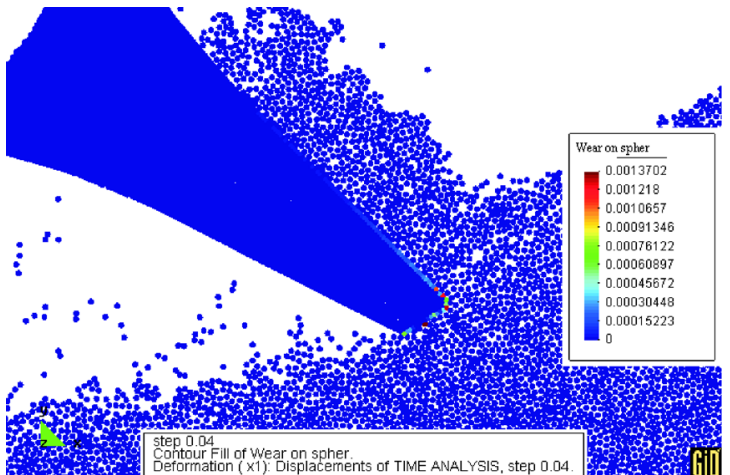

(b)

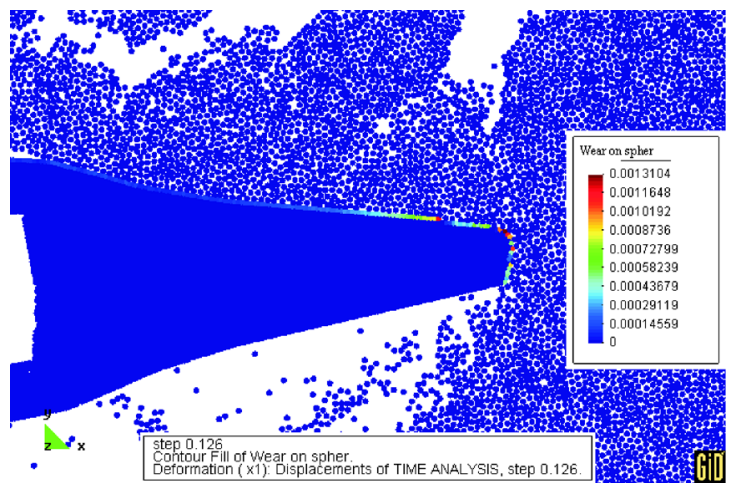

(d)

Fig. 16 Thermomechanical simulation of rock cutting with a pick of a dredge cutter head-accumulated wear on the tool surface. a $t=0.01 \mathrm{~s}$, b t $=0.2 \mathrm{~s}, \mathbf{c t}=0.4 \mathrm{~s}, \mathbf{d ~ t}=0.65 \mathrm{~s}$

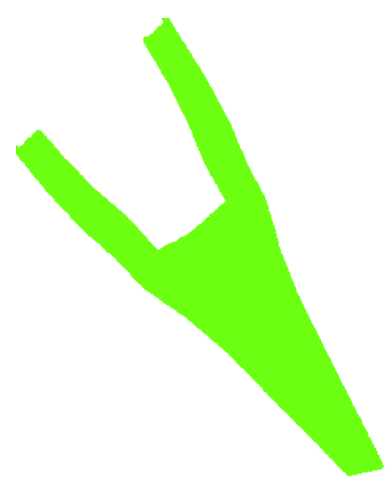

(a)

Fig. 17 Thermomechanical simulation of rock cutting with a pick of a dredge cutter head-change of the tool shape due to wear. a Initial shape, $\mathbf{b}$ shape after the first cut

In order to get quantitatively correct results the discrete element modelling should be based on experimentally measured physical parameters and should be extended on threedimensional geometry.

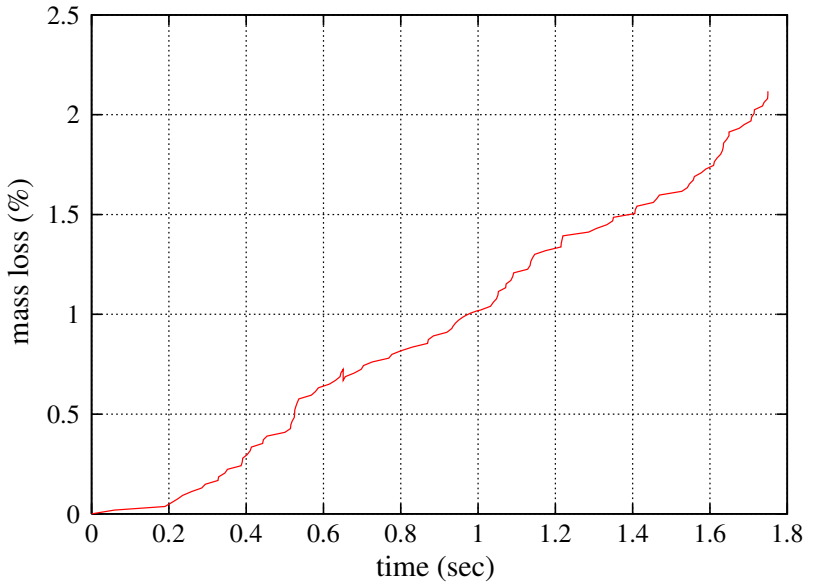

Fig. 18 Tooth mass loss during three cycles

Open Access This article is distributed under the terms of the Creative Commons Attribution License which permits any use, distribution, and reproduction in any medium, provided the original author(s) and the source are credited. 


\section{References}

1. Archard JF (1953) Contact and rubbing of flat surfaces. J Appl Phys 24(8):981-988

2. Balci C, Bilgin N (2007) Correlative study of linear small and fullscale rock cutting tests to select mechanized excavation machines. Int J Rock Mech Min Sci 44(3):468-476

3. Bilgin N, Demircin MA, Copur H, Balci C, Tuncdemir H, Akcin N (2006) Dominant rock properties affecting the performance of conical picks and the comparison of some experimental and theoretical results. Int J Rock Mech Min Sci 43(1):139-156

4. Cengel YA (2007) Heat and mass transfer: a practical approach, 3rd edn. McGraw-Hill, New York

5. Cooper MG, Mikic BB, Yovanovich MM (1969) Thermal contact conductance. Int J Heat Mass Transf 12:279-300

6. Copur H, Ozdemir L, Rostami J, Bilgin N (1997) Studies on performance prediction of roadheaders based on field data in mining and tunneling projects. In: International 4th mine mechanization and automation symposium, Brisbane, Australia

7. Cundall PA, Strack ODL (1979) A discrete numerical method for granular assemblies. Geotechnique 29:47-65

8. Eberhard P, Gaugele T (2013) Simulation of cutting processes using mesh-free Lagrangian particle methods. Comput Mech 51:261278

9. Evans I (1965) The force required for pointed attack picks. Int J Min Eng 2:63-71

10. Fakhimi A, Villegas T (2007) Application of dimensional analysis in calibration of a discrete element model for rock deformation and fracture. Rock Mech Rock Eng 40(2):193-211

11. Feng YT, Han K, Owen DRJ (2008) Discrete thermal element modelling of heat conduction in particle systems: basic formulations. $\mathrm{J}$ Comput Phys 227:5072-5089

12. Feng YT, Han K, Owen DRJ (2009) Discrete thermal element modelling of heat conduction in particle systems: pipe-network model and transient analysis. Powder Technol 193:248-256

13. Hahn M, Schwarz M, Kröplin B-H, Wallmersperger T (2011) Discrete element method for the thermal field: proof of concept and determination of the material parameters. Comput Mater Sci 50:2771-2784

14. Huang H (1999) Discrete element modeling of tool-rock interaction. Ph.D. thesis, University of Minnesota

15. Huang H, Lecampion B, Detournay E (2013) Discrete element modeling of tool-rock interaction I: rock cutting. Int J Numer Anal Methods Geomech 37:1913-1929

16. Jonak J, Podgórski J (2001) Mathematical model and results of rock cutting modelling. J Min Sci 37:615-618

17. Khair AW (1996) The effect of bit geometry on rock cutting efficiency. Appl Occup Environ Hyg 11(7):695-700

18. Korinets AR, Alehossein H, Chen L, Lim W, Baker G (1996) DIANA modeling of a rolling disc cutter and rock indentation. In: Aubertinin M, Hassani F, Mitri M (eds) Rock mechanics, tools and techniques. Rotterdam, Balkema, pp 647-654

19. Kou SQ, Lindqvist PA, Tang CA, Xu XH (1999) Numerical simulation of the cutting of inhomogeneous rocks. Int J Rock Mech Min Sci 36:711-717

20. Loui JP, Rao KUM (2005) Heat transfer simulation in drag pick cutting of rocks. Tunn Undergr Space Technol 20:263-270

21. Milanez F, Yovanovich MM, Mantelli MBH (2003) Thermal contact conductance at low contact pressures. In: 36th AIAA thermophysics conference, 23-26 June
22. Nguyen VD, Fortin J, Guessasma M, Bellenger E, Cogné C (2009) Thermomechanical modelling of friction effects in granular flows using the discrete element method. J Mech Mater Struct 4:413-426

23. Nishimatsu Y (1972) The mechanics of rock cutting. Int J Rock Mech Min Sci 9:261-270

24. Ortega A, Glowka DA (1982) Frictional heating and convective cooling of polycrystalline diamond drag tools during rock cutting. Sandia, report SAND82-0675C

25. Ortega A, Glowka DA (1982) Studies of the frictional heating of polycrystalline diamond compact drag tools during rock cutting. Sandia, report SAND80-2677

26. Oñate E, Rojek J (2004) Combination of discrete element and finite element methods for dynamic analysis of geomechanics problems. Comput Methods Appl Mech Eng 193:3087-3128

27. Rabinowicz E (1995) Friction and wear of materials. Wiley, London

28. Rojek J, Oñate E, Labra C, Kargl H (2011) Discrete element simulation of rock cutting. Int J Rock Mech Min Sci 48(6):996-1010

29. Rojek J, Oñate E, Zarate F, Miquel J (2001) Modelling of rock, soil and granular materials using spherical elements. In: 2nd European conference on computational mechanics ECCM-2001, Cracow, 26-29 June

30. Shenghua Y (2004) Simulation of rock cutting by the finite element method. In: International ANSYS conference proceedings, pp 61-71

31. Stavropoulou M (2006) Modeling of small-diameter rotary drilling tests on marbles. Int J Rock Mech Min Sci 43:1034-1051

32. Su O, Ali Akcin N (2011) Numerical simulation of rock cutting using the discrete element method. Int J Rock Mech Min Sci $48: 434-442$

33. Terreros I, Iordanoff I, Charles JL, Coupard D, Tcherniaieff S (2009) Discrete element method, a tool to investigate complex thermo mechanical behaviour: application to friction stir welding. Int J Mater Form 2(Suppl 1):573-576

34. Thuro K, Plinninger RJ (1999) Predicting roadheader advance rates. Tunn Tunn Int 6:36-39

35. Verhoef PNW (1997) Wear of rock cutting tools. Balkema, Rotterdamd

36. Wanne T (2009) Bonded-particle modeling of thermally induced damage in rock. Ph.D. thesis, University of Toronto

37. Yahiaoui M, Gerbaud L, Paris J-Y, Delbe K, Denape J, Dourfaye A (2013) A study on PDC drill bits quality. Wear 298-299:32-41

38. Yang B, Jiao Y, Lei S (2006) A study on the effects of microparameters on macroproperties for specimens created by bonded particles. Eng Comput 23(6):607-631

39. Yu B, Khair AW (2007) Numerical modeling of rock ridge breakage in rotary cutting. In: ARMA general meeting, Vancouver, British Columbia, Canada

40. Zhang HW, Zhou Q, Xing HL, Muhlhaus H (2011) A DEM study on the effective thermal conductivity of granular assemblies. Powder Technol 205:172-183

41. Zhang HW, Zhou Q, Zheng YG (2011) A multi-scale method for thermal conduction simulation in granular materials. Comput Mater Sci 50:2750-2758

42. Zohdi T (2004) A computational framework for agglomeration in thermochemically reacting granular flows. Proc R Soc Lond A 460:3421-3445

43. Zohdi T (2008) On the computation of the coupled thermoelectromagnetic response of continua with particulate microstructure. Int J Numer Methods Eng 76:1250-1279 